\title{
Pengolahan Data Pengawai Menggunakan Metode FAST Pada PT. Asia Berjaya Mobilindo
}

\author{
Titik Misriati' ${ }^{1}$ Yoseph Tajul Arifin², Haryani ${ }^{3}$, Arie Kurniawan ${ }^{4}$ \\ ${ }^{1}$ Universitas Bina Sarana Informatika \\ e-mail: titik.tmi@bsi.ac.id \\ ${ }^{2}$ Universitas Bina Sarana Informatika \\ e-mail: yoseph.ypa@bsi.ac.id \\ ${ }^{3}$ Universitas Bina Sarana Informatika \\ e-mail: haryani.hyi@bsi.ac.id \\ ${ }^{4}$ STMIK Nusa Mandiri \\ e-mail: aduhsiarie@gmail.com
}

Cara Sitasi: Misriati, T., Arifin, Y. T., \& Haryani, H. (2019). Pengolahan Data Pengawai Menggunakan Metode FAST Pada PT. Asia Berjaya Mobilindo. Paradigma - Jurnal Komputer dan Informatika, 21(2), 187-192. doi:10.31294/p.v21i2.6523

\begin{abstract}
PT. Asia Berjaya Mobilindo is one of the companies in Indonesia which is engaged in selling, maintaining and selling Mazda brand auto parts. Employee data processing at PT. Asia Berjaya Mobilindo is still conducted conventionally and creates several obstacles for employees, especially when applying for leave and salary receipt. Submission of leave addressed to HRD managers is done by using leave letters and must be submitted directly, there are delays in the distribution of salary slips and there are errors in the calculation of salaries that cause employees to receive salaries that are not in accordance with what should be received by employees. Therefore, the required information system for filing leave, salary slip and recap of employee absences in accordance with PT. Asia Berjaya Mobilindo using the Framework for the Application of System Thinking (FAST) method with a Unified Model Language (UML) diagram so that the system built is able to solve problems in employee data processing at PT. Asia Berjaya Mobilindo and makes it easy for employees to apply for leave, see payslips and see absences.
\end{abstract}

Keywords : employee, website, Framework for the Application of System Thinking, Unified Model Language

\section{PENDAHULUAN}

Pencatatan absensi karyawan merupakan salah satu faktor penting dalam perusahaan. Peusahaan dapat memantau kehadiran pegawai melalui absensi (Fikry \& Aswin, 2014), informasi yang mendalam dan terperinci mengenai kehadiran seorang karyawan dapat menentukan prestasi kerja, gaji atau kemajuan instansi secara umum.

Gaji adalah sebuah bentuk pembayaran atau sebuah hak yang diberikan oleh sebuah perusahaan atau instansi kepada pegawai. Pembayaran gaji merupakan unsur yang sangat penting bagi pegawai (Hamdani, 2005)

Cuti merupakan salah satu hak pegawai, cuti dapat digunakan oleh pegawai untuk tidak masuk kerja dengan alasan tertentu misalkan refreshing, istirahat sakit, melahirkan, menunaikan kewajiban agama, dan keperluan lain sesuai dengan ketentuan cuti pada masing-masing organisasi. Dengan performa pegawai yang baik, sebuah organisasi dapat menjalankan proses bisnisnya dan mencapai tujuan organisasi.

PT. Asia Berjaya Mobilindo adalah suatu perusahaan yang bergerak dibidang penjualan, perawatan, serta penjualan suku cadang mobil bermerk Mazda.

Permasalahan yang dimiliki PT. Asia Berjaya Mobilindo dalam pengelolaan data pegawainya masih ada yang bersifat manual seperti pengajuan cuti yaitu menggunakan kertas dimana setiap pegawai yang ingin mengajukan cuti harus mengirimkan surat yang ditujukan kepada manajer HRD, slip gaji yaitu keterlambatan pendistribusian slip gaji karyawan dimana hanya Head of HRD yang bisa mencetak dan mendistribusikan ke karyawan, lihat absensi yaitu kebanyakan karyawan yang terpotong gajinya banyak 
yang tidak tahu kenapa gajinya bisa terpotong apa karena telat absen atau tidak masuk, dikarenakan dengan sistem yang digunakan saat ini dapat menimbulkan beberapa kendala diantaranya adalah jika pihak yang berwenang tidak ada ditempat maka persetujuan cuti, slip gaji dan lihat absensi akan terhambat dan pencatatannya masih menggunakan LibreOffice Calc.

Semua pencatatan data absensi, gaji, cuti, surat ijin masih dicatat di dalam buku dan belum berbasis komputer. Hal ini dapat menyebabkan kesalahan dalam penginputan data karena tulisan yang tidak jelas (Simargolang \& Warsito, 2017).

Penelitian terkait yang mendukung penelitian ini adalah penelitian yang dilakukan oleh Hengki dan Ayu Novitasari pada tahun 2017 menyatakan bahwa sistem informasi kepegawaian yang dirancang menggunakan metode FAST dengan tools UML dapat digunakan dengan mudah, dan meringankan pekerjaan UPTD DPPKAD Pangkalpinang dalam menginput dan mencari data pegawai, membuat pengolahan data menjadi lebih efektif dan efisien, data yang disimpan di database lebih memudahkan dalam proses penyimpanan, sehingga mencegah hilangnya data dan duplikasi data (Hengki \& Novitasari, 2017). Penelitian tentang Sistem Informasi Pengolahan Data Absensi dan Pengambilan Surat Cuti Kerja yang dilakukan oleh Albertus L. Setyabudhi pada tahun 2017 menunjukkan bahwa proses pengambilan surat izin cuti kerja dapat lebih efektif dan efisien dengan sistem informasi pengolah data absensi dan pengambilan surat cuti kerja secara online (Setyabudhi, 2017). Penelitian pada tahun 2018 yang dilakukan oleh Difiansyah, Yudi Santoso, dan Nurwati tentang sistem informasi administrasi kepegawaian pada PT. Merah Cipta Media mampu meningkatkan pelayanan terhadap pegawai dan proses perhitungan cuti menjadi lebih akurat (Difiansyah, Santoso, \& Nurwati, 2018).

Berdasarkan uraian tersebut, maka rumusan masalah pada penelitian ini adalah bagaimana merancang sistem informasi pengajuan cuti, slip gaji dan rekap absen karyawan yang sesuai dengan PT. Asia Berjaya Mobilindo dengan menggunakan metode Framework for The Application of System Thinking (FAST) dengan diagram Unified Model Language (UML untuk memudahkan memudahkan pegawai dalam mengajukan cuti, melihat slip gaji dan melihat absen.

\section{METODOLOGI PENELITIAN}

Penelitian ini menggunakan metode Framework for The Application of System Thinking (FAST) dengan diagram Unified Model Language (UML) untuk pemodelan sistem. Tahapan dari metode FAST adalah:

\section{a. Scope Definition}

Penulis melakukan wawancara dan observasi secara langsung di PT. Asia Berjaya Mobilindo. Hal ini dilakukan untuk memperoleh data dalam menentukan permasalahan yang dihadapi oleh PT. Asia Berjaya Mobilindo sehingga dapat dibuat sistem sesuai dengan kebutuhan.

b. Problem Analysis

Penulis mempelajari sistem yang sedang berjalan di PT. Asia Berjaya Mobilindo dan menganalisis permasalahan yang terjadi untuk menentukan pengembangan sistem.

c. Requirement Analysis

Penulis menentukan kebutuhan sistem dari sistem yang akan dibangun.

d. Logical Design

Pada tahap ini, kebutuhan sistem diterjemahkan menggunakan Unified Model Language (UML) dan Entity Relationship Diagram (ERD).

e. Physical Design

Desain fisik dibuat berdasarkan analisis kebutuhan yang telah dilakukan.

f. Construction and Testing

Penulis membuat basis data, program aplikasi, rancangan antarmuka, dan kode program. Setelah itu, dilakukan pengujian terhadap keseluruhan sistem telah dibuat.

\section{HASIL DAN PEMBAHASAN}

\section{Scope Definition}

Ruang lingkup dari sistem pengolahan data pegawai di PT. Asia Berjaya Mobilindo dimulai dari pengolahan data pegawai, data absensi, pengajuan cuti dan penggajian pegawai sampai dengan dihasilkan laporan.

\section{Analisis Kebutuhan}

Sistem pengolahan data pengawai pada PT. Asia Berjaya Mobilindo dilakukan oleh dua pengguna, yaitu pegawai dan personalia. Pegawai dapat melakukan cetak absensi, cetak slip gaji dan pengajuan cuti melalui browser. Kebutuhan pengguna dapat dijabarkan sebagai berikut:

Halaman Pegawai:

A1. Pegawai dapat mengelola data pegawai

A2. Pegawai dapat melakukan absensi

A3. Pegawai dapat melakukan pengajuan cuti

Halaman Personalia:

B1. Personalia dapat mengelola data pegawai

B2. Personalia dapat mengelola data absensi kayawan

B3. Personalia dapat mengelola cuti karyawan

B4. Personalia dapat mengelola data gaji karyawan

Spesifikasi perangkat atau sarana yang digunakan adalah:

a. Spesifikasi Perangkat Keras

1) $\mathrm{CPU}$

2) Processor Dual Core $2.10 \mathrm{GHz}$, RAM 
3) DDR2 3 GB, Hard Disk 250 GB

4) Mouse standar

5) Keyboard standar

6) Monitor dengan resolusi layar $1366 \times 768$

7) Koneksi internet dengan kecepatan 2 Mbps.

b. Spesifikasi Perangkat Lunak
1) Sistem operasi : Microsoft Windows 7
2) Program Desain : Adobe Dreamweaver CS4
3) Bahasa Script : PHP dan HTML
4) Web Server : Apache
5) Web Browser : Google Chrome
6) Database : MySQL

\section{Use Case Diagram}

Use case diagram merupakan pemodelan untuk kelakuan (behavior) sistem informasi yang akan dibuat. Use case mendeskripsikan sebuah interaksi antara satu atau lebih actor dengan sistem informasi yang akan dibuat (Sukamto \& Shalahuddin, 2014).

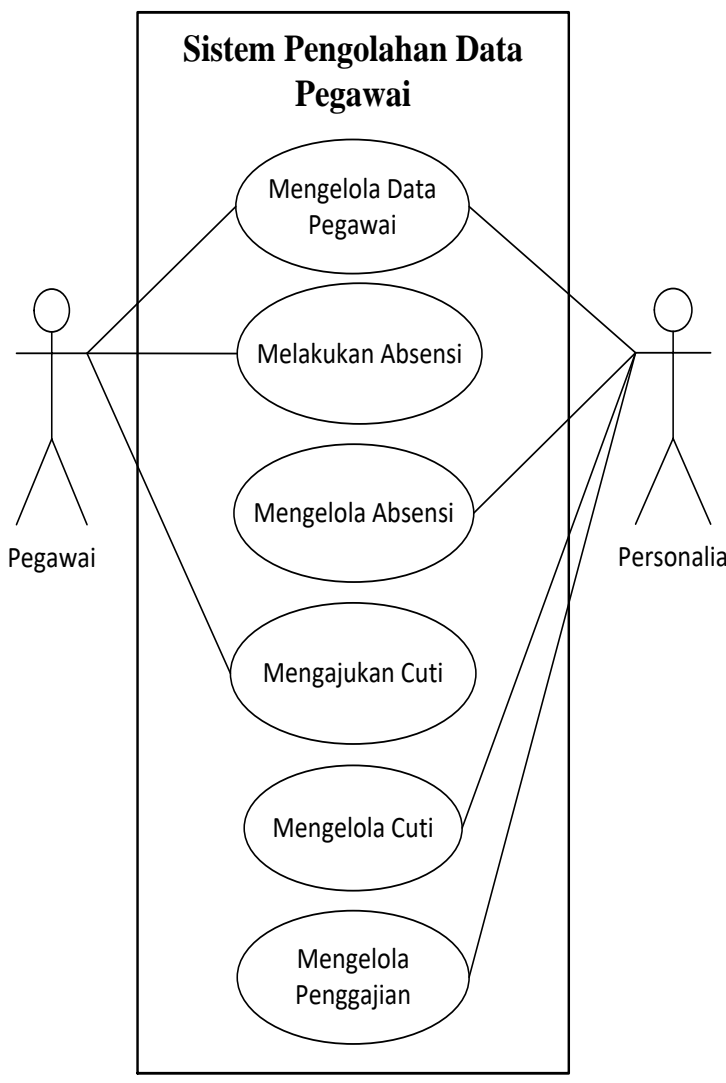

Gambar 1. Use Case Diagram Pengolahan Data Pegawai

\section{Activity Diagram}

Activity diagram menggambarkan workflow (aliran kerja) atau aktivitas dari sebuah sistem atau proses bisnis atau menu yang ada pada perangkat lunak (Sukamto \& Shalahuddin, 2014).



Gambar 2.Activity Diagram Absen

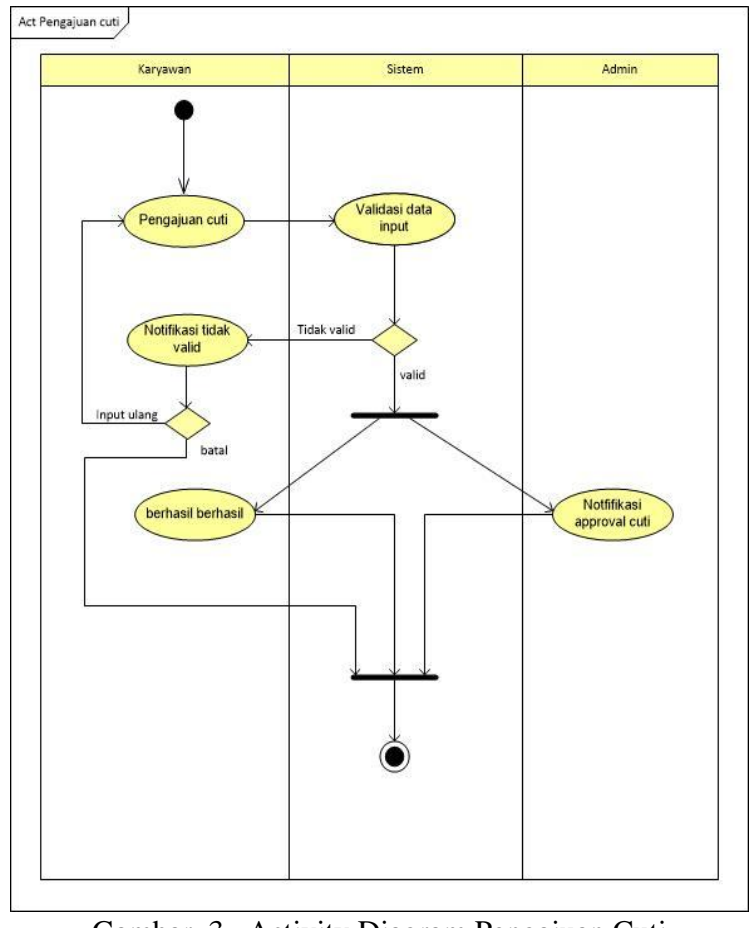

Gambar 3. Activity Diagram Pengajuan Cuti

\section{Entity Relationship Diagram}

Entity Relationship Diagram (ERD) adalah diagram yang menggambarkan keterkaitan antar tabel beserta dengan field-field di dalamnya pada suatu database sistem (Pratama, 2014). 


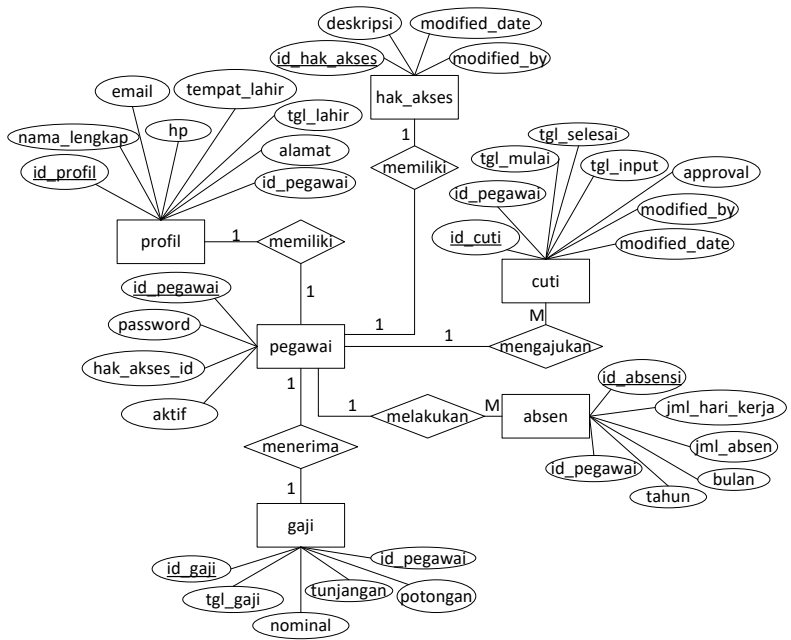

Gambar 4. Entity Relationship Diagram Pengolahan Data Pegawai

\section{Component Diagram}

Diagram komponen atau component diagram dibuat untuk menunjukkan organisasi dan ketergantungan diantara kumpulan komponen dalam sebuah sistem (Sukamto \& Shalahuddin, 2014).

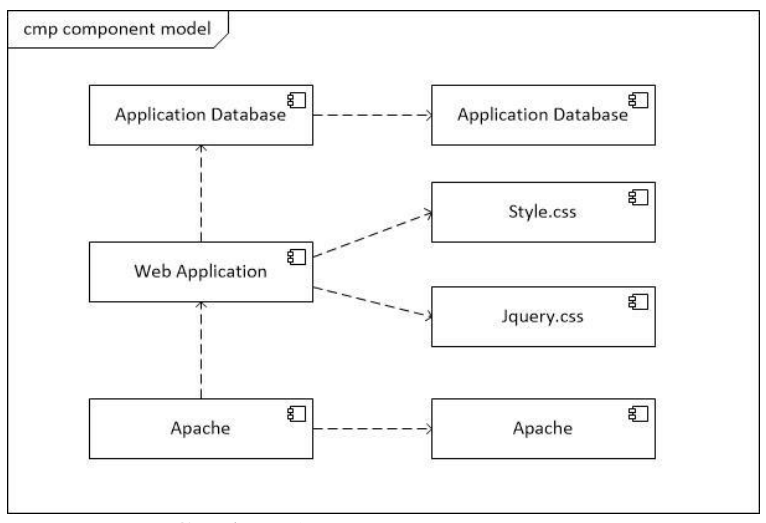

Gambar 5. Component Diagram

\section{Deployment Diagram}

Deployment diagram menunjukkan konfigurasi komponen dalam proses eksekusi aplikasi (Sukamto \& Shalahuddin, 2014).

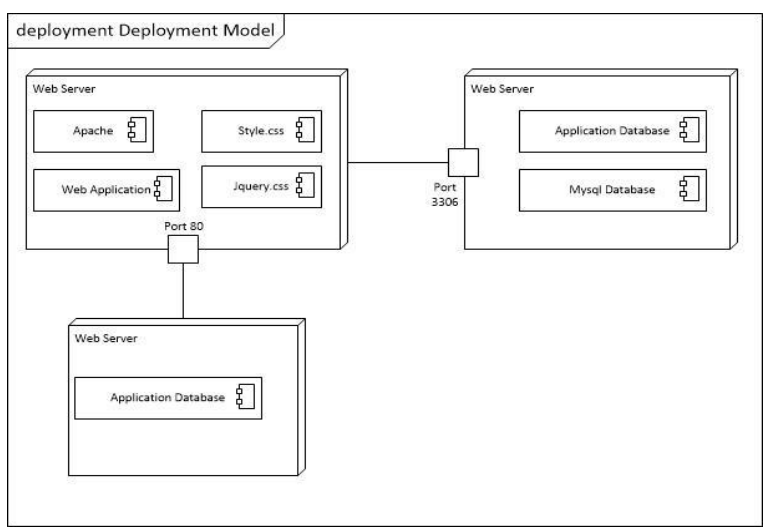

Gambar 6. Deployment Diagram

\section{Sequence Diagram}

Sequence diagram mengilustrasikan bagaimana pesan dikirimkan dan diterima antara objek dan dalam urutan apa. Sequence diagram ialah diagram yang digunakan untuk mendefinisikan input dan output serta urutan interaksi antara pengguna dan sistem untuk sebuah use case (Triandini \& Suardika, 2012).

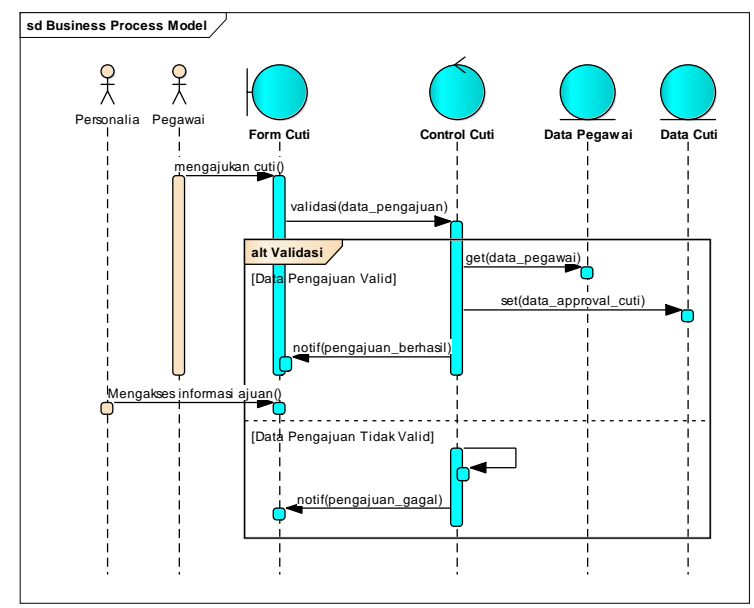

Gambar 7. Sequnce Diagram Pengajuan Cuti

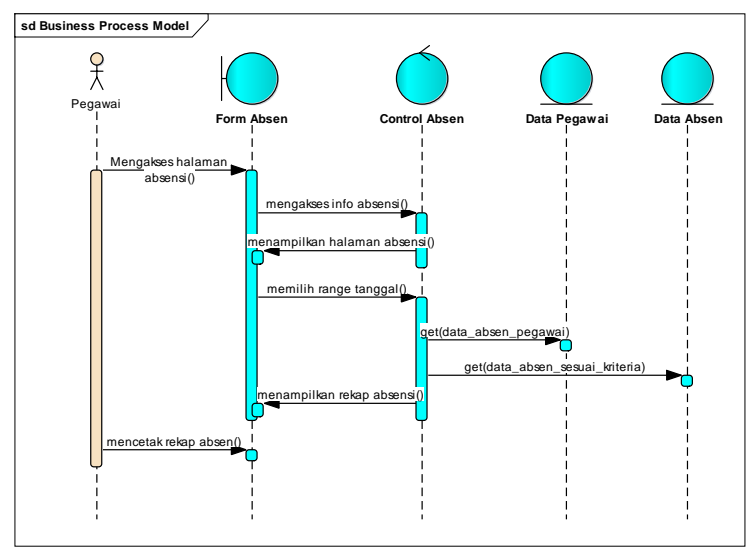

Gambar 8. Sequnce Diagram Rekap Absen

\section{User Interface}

a. Tampilan Halaman Login

Halaman ini digunakan untuk login dalam mengakses data pada sistem pengolahan data pegawai dengan memasukkan username dan password.

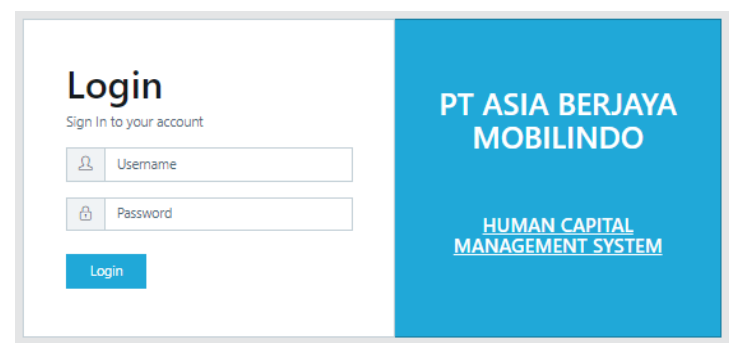

Gambar 9. Tampilan Halaman Presensi

b. Tampilan Halaman Absen

Pegawai melakukan absensi dan data absen akan disimpan ke dalam database. Absensi 
ini akan dikelola oleh personalia dan pegawai dapat melihat data absensi yang telah dilakukan.

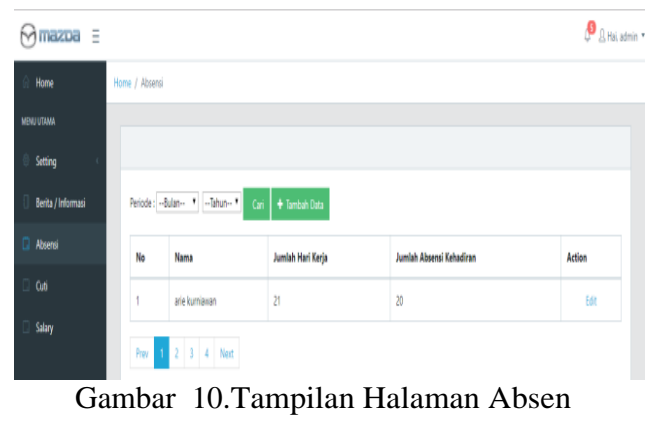

c. Tampilan Halaman Cuti

Pegawai mengajukan cuti melalui sistem dan akan diproses oleh personalia. Pegawai dapat melihat status dari pengajuan cuti.

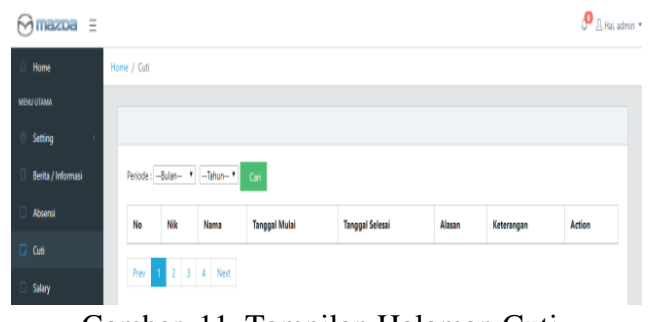

Gambar 11. Tampilan Halaman Cuti

d. Tampilan Halaman Penggajian

Penggajian dilakukan setiap sebulan sekali dan pegawai dapat melihat serta mencetak slip gaji melalui sistem.



Gambar 12. Tampilan Halaman Penggajian

10. Pengujian

Setelah program dibuat, maka dilakukan pengujian terhadap sistem pengolahan data pada PT. Asia Berjaya Mobilindo. Pengujian ini dilakukan dengan black box testing untuk mengetahui apakah sistem yang dibuat berjalan sesuai dengan proses yang diharapkan. Black box adalah pengujian yang dilakukan hanya mengamati hasil eksekusi melalui data uji dan memeriksa fungsional dari perangkat lunak (Pratama, 2014).

Tabel 1. Pengujian dengan Black Box Pengajuan Cuti

\begin{tabular}{cccc}
\hline No. & $\begin{array}{c}\text { Skenario } \\
\text { pengujian }\end{array}$ & $\begin{array}{c}\text { Hasil yang } \\
\text { diharapkan }\end{array}$ & $\begin{array}{c}\text { Hasil } \\
\text { pengujian }\end{array}$ \\
\hline
\end{tabular}

\begin{tabular}{|c|c|c|c|}
\hline 1. & $\begin{array}{l}\text { Mengosongkan } \\
\text { semua isian data } \\
\text { pengajuan cuti }\end{array}$ & $\begin{array}{l}\text { Tombol } \\
\text { simpan tidak } \\
\text { aktif dan } \\
\text { menampilkan } \\
\text { pesan "harus } \\
\text { diisi" }\end{array}$ & $\begin{array}{c}\text { Sesuai } \\
\text { harapan }\end{array}$ \\
\hline 2. & $\begin{array}{l}\text { Mengisi semua } \\
\text { isian data } \\
\text { pengajuan cuti } \\
\text { dengan format } \\
\text { Tanggal Mulai } \\
\text { kurang dari hari } \\
\text { ini }\end{array}$ & $\begin{array}{l}\text { Sistem akan } \\
\text { menolak } \\
\text { penyimpanan } \\
\text { data pengajuan } \\
\text { cuti dan } \\
\text { menampilkan } \\
\text { pesan "Tgl } \\
\text { Mulai" }\end{array}$ & $\begin{array}{c}\text { Sesuai } \\
\text { harapan }\end{array}$ \\
\hline 3. & $\begin{array}{l}\text { Semua isian } \\
\text { terisi dari data } \\
\text { pengajuan cuti, } \\
\text { lalu langsung } \\
\text { mengklik tombol } \\
\text { "simpan" }\end{array}$ & $\begin{array}{l}\text { Sistem } \\
\text { menerima data } \\
\text { dan } \\
\text { menyimpan ke } \\
\text { dalam } \\
\text { database }\end{array}$ & $\begin{array}{l}\text { Sesuai } \\
\text { harapan }\end{array}$ \\
\hline
\end{tabular}

\section{KESIMPULAN}

Berdasarkan pembahasan dapat disimpulkan bahwa:

1. Sistem pengolahan data pegawai menggunakan website dengan metode FAST dan UML ndapat meningkatkan pelayanan terhadap karyawan dalam pengajuan cuti, penggajian dan absensi.

2. Pegawai dapat mengajukan cuti secara online tanpa harus bolak-balik ke bagian personalia untuk mengetahui status ajuan cuti.

3. Pegawai dan pimpinan dapat melihat absensi yang dilakukan oleh pegawai.

4. Perhitungan gaji menjadi lebih cepat dan akurat.

\section{REFERENSI}

Difiansyah, Santoso, Y., \& Nurwati. (2018). Rancang Bangun Sistem Informasi Administrasi Kepegawaian Pada PT Merah Cipta Media Jakarta. Prosiding Industrial Research Workshop and National Seminar, 325-331. Retrieved from https://jurnal.polban.ac.id/index.php/proceedin g/article/view/1117/917

Fikry, M., \& Aswin, A. R. (2014). Jurnal Edik Informatika Pembangunan Sistem Pengolahan Data Absensi Karyawan Menggunakan Fingerprint Jurnal Edik Informatika. 1.

Hamdani, D. (2005). PERANCANGAN SISTEM INFORMASI PENGELOLAAN DATA PEGAWAI DAN PENGGAJIAN PEGAWAI (Studi Kasus: BPRS Shadiq Amanah). Retrieved from https://repository.widyatama.ac.id/xmlui/handl e/123456789/8569

Hengki, \& Novitasari, A. (2017). Analisis dan Perancangan Sistem Informasi Kepegawaian 
Berbasis Website Berdasarkan Model FAST pada Kantor UPTD DPPKAD Pangkal Pinang. Teknomatika, 07(02), 12-22. Retrieved from http://ojs.palcomtech.ac.id/index.php/teknomat ika/article/view/58

Pratama, I. P. A. E. (2014). Sistem Informasi dan Implementasinya. Bandung: Informatika.

Setyabudhi, A. L. (2017). Perancangan Sistem Informasi Pengolahan Data Absensi dan Pengambilan Surat Cuti Kerja Berbasis Web. 1(1), 11-22. https://doi.org/9786020271705

Simargolang, M. Y., \& Warsito, W. A. (2017). Analisis Sistem Pengolahan Absensi Karyawan Pada PT . Bakrie Sumatera Plantations Tbk Bunut. Jurnal Teknologi Informasi, 1(2), 114124. Retrieved from http://jurnal.una.ac.id/index.php/jurti/article/vi ew/285

Sukamto, R. A., \& Shalahuddin, M. (2014). Rekayasa Perangkat Lunak. Bandung: Informatika.

Triandini, E., \& Suardika, I. G. (2012). Step by Step Desain Proyek Menggunakan UML. In $C V$ Andi Offset. Yogyakarta: CV Andi Offset.

\section{PROFIL PENULIS}

Titik Misriati, M.Kom. Lahir di Purworejo, Jawa Tengah pada tanggal 16 Mei 1985. Lulus Program Diploma Tiga pada tahun 2007 di AMIK BSI Jakarta, Lulus S1 pada tahun 2009. Program Studi Sistem Informasi di STMIK Nusa Mandiri Jakarta, Lulus S2 tahun 2013 Program Studi Ilmu
Komputer (S2) Konsentrasi Management Information System di Program Pasca Sarjana STMIK Nusamandiri Jakarta. Menjadi dosen tetap di AMIK BSI Jakarta sejak tahun 2010 yang sekarang menjadi Universitas Bina Sarana Informatika.

Yoseph Tajul Arifin, M.Kom. Kelahiran tahun 87 tepatnya 20 September 1987 di kota Ciamis Jawa Barat. Lulusan S2 Magister Ilmu Komputer tahun 2016 program Pascasarjana di STMIK Nusa Mandiri Jakarta. Berprofesi sebagai Dosen di Universitas Bina Sarana Informatika dan staf pada Unit Lembaga Penelitian dan Pengabdian Masyarakat Universitas Bina Sarana Informatika Senang menekuni bidang pengembangan aplikasi berbasis website dengan background keilmuan sistem informasi dan ilmu komputer serta telah menerbitkan beberapa penelitian pada bidang yang sama pada beberapa jurnal.

Haryani, M.Kom, Lulusan S1 STMIK Kuwera Jakarta tahun 2006, Lulus S2 tahun 2010 Magister Ilmu Komputer di Pascasarjana STMIK Nusa Mandiri Jakarta. Menjadi dosen tetap di Universitas Bina Sarana Informatika sejak tahun 2007. Pernah melakukan penelitian mengenai Audit Sistem Informasi Akademik di SDIT Nurul Fikri Depok.

Arie Kurniawan. Lahir di Bogor pada tanggal 24 Mei 1986. Lulus dari Bina Sarana Informatika pada tahun 2013 dan melanjutkan kuliah di jenjang S1 pada STMIK Nusa Mandiri. 